\title{
Towards Leveraging Behavioral Economics in Mobile Application Design
}

Tobias Stockinger, Marion Koelle, Patrick Lindemann, Matthias Kranz, Stefan

Diewald, Andreas Möller and Luis Roalter

\begin{abstract}
People do not always think and behave rationally. Behavioral economics has produced theories to explain when and why people make such allegedly irrational decisions, for example if it comes to spending money. However, humans tend to use reference points to judge and decide. Nowadays, mobile devices can work as flexible tools to create reference points thus supporting decisions without being explicit about it. We discuss if and how mobile apps can influence decision making. As a consequence, apps can be built to better fit into the decision making progress. We argue that applying concepts from behavioral economics can increase user experience in a subtle manner.
\end{abstract}

\section{Introduction}

Humans tend to believe that their actions are mostly rational and justifiable. However, psychology research from the last 40 years has produced a growing list of cognitive biases which impact our rationality. Even the sheer belief that one does not show as many biases as other people is a cognitive bias itself (Pronin \& Kugler 2007). Most of the biases are usually harmless and do not affect mental health. However, some of them $d o$ become dangerous and reduce life quality, because cognitive biases can influence how we perceive e.g. stress, addictions or depression (Muran \& Motta 1993). Thus, we believe that even reflecting on the more harmless cognitive biases might lead to different behavior and eventually to an improved life.

Tobias Stockinger, Marion Koelle, Patrick Lindemann, Matthias Kranz University of Passau, Innstr. 43, D-94032 Passau, e-mail: <firstname.lastname>@uni-passau.de Stefan Diewald, Andreas Möller, Luis Roalter

Technische Universität München, Distributed Multimodal Interaction Group, Arcisstr. 21, D-80333

Munich, e-mail: stefan.diewald@tum.de, andreas.moeller@tum.de,roalter@tum.de 


\subsection{Observations of Irrationality in Everyday HCI}

Behavioral Economics (BE) is a rather novel field when applied to Human-Computer Interaction (HCI). In this chapter, we present a selected set of applications to highlight new opportunities that arise from this research direction. Designing for bounded rationality is a real challenge that we are only beginning to undertake. Yet, in interaction design we sometimes encounter situations in which designers cannot comprehend the users' behavior entirely. Norman (2007) emphasizes findings from Tractinsky (1997) showing the following: User interfaces that only differ in aesthetics, but not in functionality or number of elements, appear to be easier to use if they were only designed in a more beautiful way. The subjects in the corresponding user studies strongly followed their emotions which lead them to assess the usability of an ATM in an allegedly irrational way. Consequently, we can conclude from those findings that irrationality is not just the outcome of our inclination to act intuitively without further reflection (Kahneman 2011, p.96), but also results from emotion. More examples of apparent bounded rationality follow.

\section{Notifications}

In both desktop and mobile applications we often can opt to get notified on certain events: incoming emails, tweets and Facebook status updates, changes in a shared Dropbox folder or reminders for an upcoming football match in a calendar application are just a few examples of everyday notifications. Some of them are even "opt-out", meaning they are turned on by default and require user interaction to get rid of them. The problem is that activating many notification services disrupts people's work flow and distracts them very often. One question that we like to pose in this matter is: why do people believe that notifications are beneficial when in fact notifications are an enemy of productivity and concentration?

\section{Progress Bars}

From time to time, working with computers requires a waiting time during which progress bars give feedback of the current system status. This is in line with Nielsen's usability heuristics (Nielsen \& Molich 1990). However, is it not somewhat strange that many of us observe such progress bars even if they take more than just a few seconds? One could easily switch to another task. Hurter et al. (2011) tried to augment progress bars with temporary tasks, such as tagging pictures in a media library. The need for progress bars could be explained with mental accounting theory (see Section 3.1). 


\section{App Return Policy}

The Google Play Store has a 15 minute return policy for paid Android apps ${ }^{1}$. Theories from behavioral economics indicate that it is very unlikely that users decide on this refunding option, because it is difficult to return something once we have it (Ariely et al. 2005, Kahneman \& Tversky 1979). Behavioral economists call this the endowment effect combined with loss aversion (more details in Section 3.2).

\section{Computer Help}

Being an expert in computer science (or simply having such reputation) eventually leads to phone calls asking for computer help ("Can you fix this?", "I don't know how to set up my printer, can you do this the next time you're here?"). However, novice users sometimes seem to forget that a little exercise and online research might eventually do the trick. They are biased by their own beliefs that they cannot achieve their goals. Once they fail, they attribute that failure more easily to their lack of knowledge. Psychologists call this the confirmation bias (Kahneman 2011, pp. 81-82). In other words, people jump to conclusions very quickly if they find the slightest evidence supporting their attitude.

\subsection{Chapter Overview}

In the following section (Section 1.3), we clearly formulate the contributions of this chapter in the area of behavioral economics in HCI. In Section 2 we provide a review of related research and findings from the fields that are most relevant for this work: Persuasive Computing (Section 2.1), Gamification in mobile applications (section 2.2) and our main topic Behavioral Economics (Section 2.3). Having discussed the theoretical aspects of our propositions, we present our "MoneySaver" app in more detail before we report and discuss its evaluation (Sections 5 and 5.3). Finally, we conclude by summarizing the presented ideas and by giving an outlook to our future work (Section 6).

\subsection{Contribution}

In this book chapter, we contribute a thorough review of behavioral economics theories and their potential applicability to $\mathrm{HCI}$ in a mostly mobile scenario. We analyze allegedly irrational human behavior while using mobile applications. Based on this analysis, we demonstrate how to implement paradigms from behavioral economics

\footnotetext{
${ }^{1}$ https://support.google.com/googleplay/answer/134336?hl=en, last accessed on August 062013
} 
to create persuasive, gamified applications. Furthermore, we elaborate on the design rationale for financial planning apps.

Persuasive systems often assume that their users act rationally. This assumption leads to the design of triggers to which rational people might respond. However, we argue that persuasive computing needs to address the quirks of the human mind including irrational behavior and biases in cognition. Applying BE to HCI leads to a more holistic approach to persuasion methods. Not only is it possible to motivate long-term behavior change. We also are able to foster irrational behavior without wanting to turning it into rational behavior, never forgetting to design for the benefit of users. The simplest example for this effect are defaults. Designers do not want users to change the proposed parameters, i.e. the users can keep up with their behavior by following the default. We try to further illustrate the divergence between our work and traditional persuasive computing in the remainder of this chapter. 


\section{Literature Review}

It is possible to categorize our work under persuasive computing. However, we add further elements from gamification and behavioral economics to generate a new idea of contemporary persuasive technology. In this section, we review related work in the corresponding fields to lay the basis for our research direction.

\subsection{Persuasive Computing}

Persuasive computing has had a long history and manifests in many dimensions. Back in 2002, Fogg became a vanguard to address persuasion through computers to nudge users towards a specific behavior and/or attitude (Fogg 2002, p. 1). Ever since then, many forms of persuasive systems have emerged. Such systems can motivate behavior change for the users' own good, e.g. in health and fitness ("self shaping" (Moraveji et al. 2011, Consolvo et al. 2006)) or security (Maurer et al. 2011). Besides, other persuasive systems also nudge users to act more environmentally friendly (Meschtscherjakov et al. 2009). Sometimes it is the same systems that use gamification to become more persuasive (further examples in Section 2.2).

Researchers have been trying to motivate behavior change for the benefit of the users. For example, Consolvo et al. (2009) elaborated a set of design goals for Ubiquitous Computing (UbiComp) systems with the intention to help the users maintain a physically active lifestyle. They, too, relied on theories from psychology, such as the Goal Setting Theory and the Cognitive Dissonance Theory, to generate new design strategies. In a long-term experiment they report on their UbiFit Garden, a visualization of the user's physical activity measured through a fitness device, which could also be classified into a gamified mobile app. Their results indicate that such mobile systems were successful in motivating behavior change. Although their studies were carried out over three months, the long-term effects of this kind of persuasion remain questionable. Thus, such findings make way for further research using some of the proposed design strategies.

Some other, non-gamified persuasive systems, which intend to create benefits for the users, rely on subtle clues to nudge their users to a certain behavior. For example, Maurer et al. (2011) developed a system to subtly raise awareness of the SSLencryption status of a website and thereby nudged people to act more cautiously in those situations. The SSLPersonas indicated the SSL status through changing the browser's skin when there is an active or broken SSL connection. In a long-term field study, they gathered evidence that such visualization methods are sufficient to fundamentally change the way people use the Internet.

An exemplary persuasive system, that engages for a greater goal than one's own, is UbiGreen by Froehlich et al. (2009, 2010). This mobile application semiautomatically tracks individual transport behavior. Also, it displays engaging imagery and context-based information to encourage the user to choose "green transportation" more often. Their qualitative results from the corresponding field studies 
indicate a positive user acceptance. However, the papers date back to 2009, respectively 2010. In the very fast-paced area of mobile devices, the current state-of-the-art mobile technology could deliver further insights on green transportation behavior, because smartphones have drastically gained momentum since then. This leaves room for additional research in this area, which is already undertaken by various research groups.

Opposed to the systems described above, some persuasive systems go further such that they explicitly communicate their persuasive nature, almost as saying "we are here to help you change your behavior, because you should". "Commitment devices" fall into that category because they act as an external watchman to motivate self-discipline. Yet, Moraveji et al. (2011) mention an important concept which one must bear in mind when designing commitment devices: Users tend to attribute successful behavior changes mostly to their own self-discipline - and not to the tools that helped them with this achievement (Fundamental Attribution Error, (Ross 1977, p. 184ff)). This implies that it takes a high degree of self-reflection to acknowledge that a persuasive system has succeeded. Another persuasion bias comes into play when we take a look at interface design. Nice-looking graphical user interfaces (GUIs) are more likely to be perceived as usable (Norman 2007, Tractinsky 1997) than their less stylish counterparts. Therefore, they seem to persuade people to use them instead of others. As a consequence, the designers of persuasive systems need to make strong efforts on their aesthetics to amplify persuasion.

\section{Distinction}

Our work in some ways differs from persuasive computing as it is generally understood to this point. Opposed to the notion that persuasive technology targets a change in people's attitudes or behavior, we focus on the reassurance and amplification of certain behavior. Hereby, we anticipate anomalies and biases in the users' actions and use them for the users' benefit. However, there is no implied intention to motivate a change in those actions or attitudes as persuasive computing would try.

\subsection{Gamification in Mobile Applications}

First of all, we would like to shed light on the characteristics of gamification. Most often, one finds gamification to be "the use of game design elements in non-game context" (Deterding et al. 2011, p. 10). Marczewski (2012) augments this description with the intentions behind gamification:

"[Gamfication is] the application of gaming metaphors to real life tasks to influence behavior, improve motivation and enhance engagement." (Marczewski 2012, p. 4)

From this definition, we can see that behavioral change appears to be a trait that persuasive computing and gamification share. The discriminatory power between 
persuasive systems and gamification is, therefore, very low. One might even say that gamified services are persuasive per se, which we are about to illustrate in this section.

The past decade, gamification has slowly started to intrigue both researchers and practitioners and it was not until $2010^{2}$ that it has become a kind of buzz-word (Zichermann \& Cunningham 2011). In this section we take a quick look at the domains in which gamification is applied at the time of writing this chapter ${ }^{3}$.

\subsubsection{Training and Exploration}

A first theme that we found while reviewing relevant literature is training and (guided) exploration. Reading a manual is often cumbersome and time-consuming. However, using a particular feature-loaded device, like an in-car entertainment system, requires the user to quarrel with printed instructions, which may often decrease the user experience. Therefore, gamification appears to help in this kind of situations as suggested, for example by Diewald et al. (2012). They propose a novel way to increase the readiness to explore natural user interfaces (NUI) in an automotive context. To achieve a certain user behavior, badges and level-ups are awarded on certain occasions without distracting the driver from the road. This approach is comparable to other tactics found in, e.g., Foursquare ${ }^{4}$ and similar services. A second example for gamification in exploration is the OrientationPassport by Fitz-Walter et al. (2011). It is a smartphone application targeted at students who are new to a university campus. It is not uncommon for universities to welcome their new students by organizing guided tours and distributing informative material to help them get around more quickly. The orientation passport application supports this initiation phase by engaging freshmen to explore the campus site and public transport system. Badges are awarded for certain activities, e.g. checking into certain events through the app. Preliminary results show that the design concept adds value to existing orientation phases but the chosen incentives were not entirely successful.

\subsubsection{Self Shaping}

Gamification is believed to be a strong motivator, because humans like competing, winning and comparing. Therefore, individual sports like jogging can also profit from such elements. That is why there are a few dozen gamified applications that target sports activities. Endomondo ${ }^{5}$, Runtastic ${ }^{6}, \mathrm{Nike}^{7}{ }^{7}$ (just to name a few) all

\footnotetext{
2 http://www.google.com/trends/explore?q=gamification, last accessed on August 82013

${ }^{3}$ Extrapolating the Google Trends Page for "Gamification" leaves us to believe that gamification will have an impact on even more domains in the future.

${ }^{4} \mathrm{https}: / /$ foursquare.com/, last accessed on September 192013

${ }^{5} \mathrm{http}: / / \mathrm{www}$. endomondo.com/, last accessed on September 052013

${ }^{6} \mathrm{http}: / /$ www.runtastic.com/, last accessed on September 052013

${ }^{7}$ http://nikeplus.nike.com, last accessed on September 052013
} 
offer the users to track and compare their data with others. Some of those apps propose challenges to the (hobbyist) athletes to boost intrinsic motivation. With most apps, it is also possible to compare one's own achievements to those of friends for the same reason.

Other commercial apps take the users outside and reward - through gamification physical activity in a more subtle way, i.e. the primary intention of those apps is not physical activity per se. Geocaching ${ }^{8}$ is a classic example that falls into this category, while Ingress ${ }^{9}$ is a very recent manifestation of an app that simply brings along physical activity. It is a location-based game that needs the users to walk around town to be able to play the game.

\subsubsection{Research}

Conducting HCI research requires testing with people. For user study participants, taking part often entails deliberately spending time in laboratories along with only moderate compensation. Testing prototypes in the field while still research is ongoing, is not trivial either. This problem was addressed by Kranz et al. (2013). The research topic was the adoption of Near-Field Communication (NFC) applications among smartphone users.

\subsubsection{Education}

Beside the need to physically shape oneself, gamification drives both self-education and knowledge transfer. In a mobile computing context, we can observe how certain apps utilize gamification to foster learning and exercising. For instance, DuoLingo ${ }^{10}$ awards badges for successfully accomplished lessons. Also, it gradually reveals more lessons as the user earns points to unlock higher levels (which in fact are language-skill levels). Gamification here keeps the learners motivated and thus helps them get to their goal more comfortably. The "Read Faster" application, as the name suggests, trains reading skills. It uses scored exercises that resemble a competition against the clock. If one completes a set of exercises, bonus training sets are unlocked. Figure 1 shows screenshots of those two apps that reveal their gamified nature. Applications for gamification in knowledge transfer contexts are addressed in detail in the EDUCATION section of this book.

\footnotetext{
${ }^{8}$ http://www.geocaching.com/, last accessed August 82013

${ }^{9}$ http://www.ingress.com/, last accessed August 82013

${ }^{10} \mathrm{http} / / /$ www.duolingo.com/mobile, last accessed on August 142013
} 


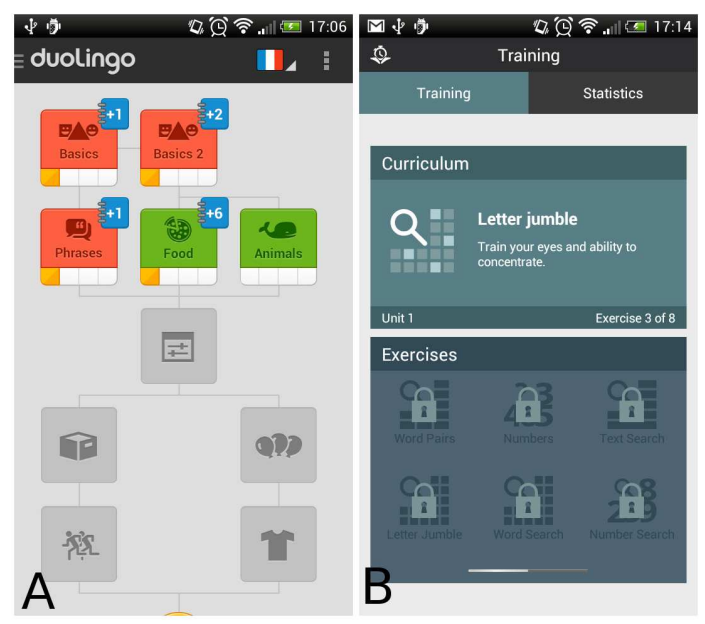

Fig. 1 Gamified educational apps (A) duolingo (B) Heku.IT Reading Trainer. Color is used in (A) to visualize the progress in learning a language. In (B) the lock indicates that corresponding exercises are not available yet. Continuing with the training unlocks them.

\subsubsection{Gamification in Business Practice}

A last area, in which gamification plays an increasingly significant role, is business practice. More and more services become gamified to create customer loyalty and to engage people. Foursquare is perhaps the paragon of a business model that utilizes gamification to market advertisement and coupons to customers. There are even ready-to-use frameworks, e.g. Badgeville ${ }^{11}$ to integrate gamification into existing browser or mobile platforms, whatever they may be. This aspect of gamification, however, goes beyond the scope of this chapter. We therefore point the reader to the related chapters within this book.

\subsection{Behavioral Economics and Psychological Computing}

Behavioral economics has been a topic since the 1980s, but was only recently investigated in $\mathrm{HCI}$ as part of the psychological and persuasive computing movement. Bao et al. (2013) look at the possibilities of psychological computing to predict user behavior for mobile media usage. They investigated how paradigms from behavioral economics can be used to nudge users to pre-fetch videos on their smartphone while they are still connected to a WLAN. This way, they propose to reduce mobile network traffic in 3G \& 4G networks, which is, despite novel communication technologies, still a major issue, as both content size and usage grow even faster.

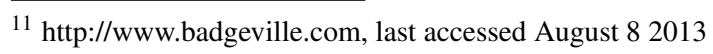


Another application for psychological computing they mention is intelligent driver assistance, sometimes referred to as advanced driver assistance systems (ADAS). Driving a car on highways is a monotonous task. If the driver shows signs of dozing off, an aware system could display intentional diversions, e.g. imagery of deer on a head-up display, to cautiously increase alertness. Performing another evaluation under different conditions with the Lane Change Test (LCT) (cf. Mattes \& Hallén (2009)) could show us further evidence for the need of psychological computing in this domain.

Lee et al. (2011) explicitly took a behavioral economics approach towards creating persuasive technology for healthy eating. In their work, they make use of a set of biases which are explained by behavioral economics: the default bias, presentbiased preferences (O'Donoghue \& Rabin 1999) and asymmetrically dominated choices (we come back to these topics in Section 3). Their approach consisted of studying how people are influenced by certain biases when opting for healthy eating. In their first case study, they observed which food people chose if they had to either choose a couple of weeks in advance or one week at a time. Simonson (1990) explains that people seek more variety when choosing in advance, whereas they fall back to the same option when the same choice re-occurs after a while. This phenomenon was corroborated by the studies by Lee et al. (2011). Not only were subjects biased if they were asked by an experimenter about their food choice, but also if they had a robot deliver their food or when ordering on-line. The corresponding studies motivate further investigation of behavioral biases in interaction design.

Personal Finances

Our work utilizes examples from a personal finance context, where there are already numerous professional software solutions for the end user. Such tools allow us to both plan and analyze our monthly spendings. Prominent examples that exhibit constructs of behavioral economics are Quicken ${ }^{12}$, its cloud-based spin-off Mint ${ }^{13}$ or Starmoney ${ }^{14}$. Those services underline mental accounting techniques (see Section 3.1) to inform the users about their spending behavior. However, it is difficult to find a concrete call-to-action - the interpretation of data is mostly done by the users, even if transactions are already categorized automatically. Yet, Mint uses scores to rate the financial performance of the users and goes beyond categorizing in to budgets: it awards "Mint points" for good behavior (i.e. financially "responsible" transactions when users succeed to keep their self-set limits) which is also visualized to give feedback ${ }^{15}$. The responsible rating algorithms, however, remain intransparent.

\footnotetext{
12 http://quicken.intuit.com/, last accessed August 082013

${ }^{13}$ https://www.mint.com/, last accessed August 082013

${ }^{14} \mathrm{http}: / /$ www.starmoney.de, last accessed August 082013

${ }^{15}$ Dole, A. (2010) 'Gaming for Behavior Change',http://method.com/pdf/10x10/Method_10x10_Gaming_for_Behavior_Change.pdf, last accessed September 052013
} 


\section{Behavioral Economics Apps}

The Duke Center for Advanced Hindsight ${ }^{16}$ has started to build a couple of iOS applications which leverage behavioral economics. However, to this point we could not find scientific publications reporting on findings made via those apps.

\section{Context Changes in Mobile Scenarios}

The core topics in behavioral economics and the related psychology research are judgment and decision making, especially biased decisions. Kahneman (2011) informs us that decisions are made either intuitively (fast) or with mental effort (slow). But even after evaluating the parameters before making a judgment, the choice is biased by the surroundings, i.e. priming through the environment. Kahneman states that judgment is inconsistent and unreliable to a high degree. This implies that even small changes in the environment might lead to a different judgment, for example a small breeze on a hot day might make you feel better and induce a different behavior in that very moment (Kahneman 2011, p. 225). Transferring this thought to mobile computing, where the context rapidly changes, means that we must rethink interaction design. We might do so by reacting to continuously changing priming and inducing reactions to changes in judgment in our systems.

\footnotetext{
${ }^{16}$ http://advanced-hindsight.com/, last accessed on August 142013
} 


\section{Behavioral Economics in Mobile Experience Design}

In this section, we first describe the principles of behavioral economics in detail, which afterwards allows us to present usage scenarios in a technology-driven environment. Thereby, we discuss how the findings transfer to the usage of computers and mobile devices in particular.

\subsection{Mental Accounting}

The first paradigm of decision making that we would like to address is mental accounting. It is one of the key principles of behavioral economics. Thaler (1999) defines mental accounting as follows:

"Mental Accounting is the set of cognitive operations used by individuals and households to organize, evaluate, and keep track of financial activities." (Thaler 1999, p. 182)

Simply put, mental accounting deals with the fact that people tend to categorize their spendings (and earnings) into budgets (mental accounts) for example household, leisure, mobility, etc. On the one hand, this paradigm can be regarded as a way to positively enforce self-control, because it can avoid overspending. On the other hand, it might be considered as irrational behavior: In a wallet, money is just a collection of bills, coins or a simple number in a bank-account. It has no category and is a mere means of exchange, which is referred to as fungibility (Wilkinson \& Klaes 2008, p. 225). Thus, people can just take their money and spend it in the moment when they need it and on whatever they need - regardless of the mental account. It therefore makes no rational sense to stop spending in one category because the budget is exhausted though the absolute amount of money is positive. Therefore, one might interpret mental accounting as a simple variant of budgeting, but there is more to it. Thaler (1999) gives us an example for irrational budgeting as mentioned above. He describes a study in which the participants were asked to assess the likelihood to buy baseball tickets for $\$ 50$. Half of the group was told that they had already gone to a baseball game the same week, the other half was told that they got a $\$ 50$ parking ticket during that week. The latter group was significantly more likely to buy the baseball tickets, although their financial situation is identical to the first group. The only difference is the perceived "overspending" in that category, which can be thought of as irrational behavior.

Mental accounting can be explained using a number of psychological effects that impact rational behavior. In the following, we briefly describe some of those effects.

\section{House Money}

One situation in which mental accounting plays a role can be observed when people receive unforeseen gains. When people win a bet or a lottery, their financial situa- 
tion immediately improves. Yet, the gain is treated differently compared to the rest of their budget. Often, people tend to spend this money differently or keep it in a different pocket, which is referred to as the "house money effect" (Thaler 1985). The additional gain can be used to bulk up a mental account to rationalize overspending or a risky investment.

Humans learn mental accounting only by observing behavior (Thaler 1999), most likely from our parents and surroundings. Opposed to industrial financial accounting there are no rules to follow in order to organize our budgets. Not only do we learn to budget our money, but also our time, which Saini \& Monga (2008) showed.

\section{Sunk Costs}

Having invested in one mental account might not have led to returns. However, one has already committed to this investment and hopes to break even. Simply put, the rationale behind this behavior is thinking "I have already put so much into this, I might as well continue." In our context, we could exploit this effect in gamification or self-tracking applications. Let us assume a progress bar shows how the user is doing in saving up her money. By applying a non-linear scale, (e.g. a logarithmic scale) the progress bar could have a progress of $25 \%$ in the center and scale the remaining $50 \%$ on the right hand side. That way, we could convey the notion of having already invested into that and "that the end is not too far", so we would expect the users to keep up with this task falling prey to the sunk costs fallacy. Furthermore, it was shown that people are eager to use things more often if they had paid a lot for them (high sunk costs), thus potentially exceeding the budget of a mental account (Thaler 1999). Trying to make more frequent usage seems to justify overspending but may be considered as irrational.

\section{Payment Decoupling}

Mental accounting is also influenced by payment modalities. It has been shown that people like to spend before rather than after consumption. If we pay in advance, we perceive consumption more enjoyable (Shafir \& Thaler 2006). Having made an investment, people have already booked it to a mental account, even if actual consumption comes much later. Thaler (1999) puts it like this:

"Note that this mental accounting transforms a very expensive hobby into one that is 'free'."

(Thaler 1999, p. 192)

Beside temporal payment decoupling, paying by credit card has another impact on the perception of spending: Accumulation minimizes the "pain of paying"17, i.e. credit card bills accumulate many transactions. As Thaler (1999) illustrates, paying $\$ 50$ hurts more than seeing the same $\$ 50$ appear in a $\$ 939$ credit card bill. Paying a higher sum just once hurts less than spending smaller amounts again and again.

\footnotetext{
${ }^{17}$ http://danariely.com/2013/02/05/the-pain-of-paying/, last accessed August 092013
} 
Generating ideas for applications in our field of interest, we can take a look at the temporal environment in which the users perform transactions. This follows the notion of Ariely's "Self-Control Credit Card" (Ariely 2009). Let us assume the user finds herself at a ticket office purchasing two concert tickets by credit card. A linked service might instantly recognize the purchase and categorize it into "leisure" expenses. Via a push message, the smart phone displays a suggestion to save a random amount of money just at that moment. We expect the shopper to follow the advice and perceive the extra expense as less unpleasant.

\subsection{Loss Aversion as Gamification Factor}

Another factor which we believe to play a special role for gamification is loss aversion, which descends from Kahnemann \& Tversky's prospect theory (Kahneman $\&$ Tversky 1979). This phenomenon describes the discrepancy between perceived intensity in gain or loss of things people own (Ariely et al. 2005). In other words, people do not want to lose what they already have and keep the status quo (statusquo bias). It comes in another variant called the endowment effect. Here too, the theory indicates that once people own anything - a car, a house or even just a bottle of wine - they endow on that particular good. As a result, if asked to sell the respective belongings, people tend to exaggerate the price by overestimating the objective value for others. The latter are only willing to pay a fraction (e.g. in case of a car) of what the owners would like to receive. A similar principle occurs for investments: Losing 5\% in stock value has a higher emotional impact than gaining 5\% in stock revenue. As a last example, frequent flyers are awarded a "Gold Status" for their loyalty to an airline. This status only valid for a certain time. Presumably, the flyers choose the same airline all the more once they have reached this prestigious status.

\section{Badges and Trophies}

Furthermore, people endow on things that they have - it does not matter from where they received the goods. The mere fact of possession changes their perspective and the perceived value of the item is much higher than that of a neutral observer.

Trophies in games and gamified services might have a similar effect. Usually, only one user at a time owns a particular trophy. As soon as the trophy changes ownership, the new owner is likely to appreciate it more than the hundreds or thousands of users that do not really care or know about this reward. However, if that trophy allows users to unlock higher levels, it might become more valuable. 


\subsection{The "IKEA-Effect" in Gamification}

Behavioral economists often investigate how humans overestimate and overvalue things. Norton et al. (2012) looked at how people become attached to things that they did not create from scratch but with a "box of bricks". Their results show that once it takes just a few steps to complete a project, e.g. building an IKEA wardrobe (hence the name), people overestimate its objective value. Bringing the IKEA effect to our studies, we can observe how some app developers utilize in-app purchases either to drive their earnings or to unlock additional functionality of an app. For example, if a specific game level is too tedious, some games offer to buy virtual currency to unlock achievements or to level-up. Such virtual currency can be obtained simply by playing the game. Thus, combining "paid" and "earned" credits (note the mental accounting here) can help the player justify his or her cheating.

Successful gamification might take advantage of this knowledge and increase user experience by refraining from paid-only functionality. We assume that earning virtual currency, such as badges or reputation points, drives the IKEA effect and helps to get people attached to an application. This is especially important if it is a persuasive system for self-shaping and greater good, because it keeps up motivation and self control.

\subsection{Framing Effects}

Prospect theory forms the basis for the research of framing effects (Kahneman \& Tversky 1979, 1984). Framing effects explain why people make inconsistent choices when their information is presented in different ways. For example, in an experiment by Gächter et al. (2009) significantly more PhD students signed up for a conference early if the "fee will include a penalty for late registration" compared to when there was "discounted conference fee for early registration". We continue by shortly describing two exemplary dimensions of framing.

\subsubsection{Anchoring}

The first type of framing effect that we try to address is anchoring (Kahneman 2011, pp. 119). Anchoring theory tells us that our choices and especially estimations are influenced by almost any information that is present in the context. Thus, it can also be seen as a form of priming (Kahneman 2011, p. 122). An anchor acts as a point of reference to base our decisions on and it does not have to be consciously processed. Asking a group of students to write down their social security number showed that this random piece of information is enough to create a reference during an anonymous, independent auction (Ariely et al. 2003). Those students who had a higher number were inclined to make higher bids than the ones with lower numbers. Kahnemann (2011, p. 122) gives us another simple example for anchoring: 
Was Gandhi more or less than 144 years old when he died?

How old was Gandhi when he died?

Chances are that people overestimate Gandhi's age once they are asked these questions in this order ${ }^{18}$.

\subsubsection{Asymmetric Choice in Settings-Menus}

A special kind of framing effect is the asymmetric choice effect. It occurs for choices under uncertainty and can be described as follows. When presented with options, humans try to establish an association to previous choices. If this fails, some other anchor or point of relevance influences the choice. In an asymmetric choice, at least two of the options are more similar than others, making it easier to compare them and harder to compare with other options. Let us look at the example that Dan Ariely provides (Ariely 2009, p. 111). A newspaper offers three subscription models:

A Online subscription for $\$ 59$ p.a.

B Print subscription for $\$ 125$ p.a.

C Print + Online subscription for $\$ 125$ p.a.

The print plus online subscription $[\mathrm{C}]$ is objectively a better bargain than the sole print subscription $[\mathrm{B}]$, because they both cost the same. However, the fact that they cost the same makes $[\mathrm{B}]$ and $[\mathrm{C}]$ more easily comparable and thus the print-only subscription [B] does not appear as attractive. In fact, option [B] becomes the negative version of $[\mathrm{C}]$, so we could say that the print plus online subscription is the real option [B] and the pure print subscription is [B-], which gives us an option set of [A, B-, B]. Now option B dominates and makes this choice asymmetric. Bringing this paradigm to persuasive computing immediately seems possible in options and settings menus. User experience designers can nudge their users by adding another, more easily comparable option which in turn is less attractive than the default.

\footnotetext{
${ }^{18}$ Just to resolve the puzzle: Gandhi died at the age of 78
} 


\section{Implementation of Selected Concepts for a Case Study}

To investigate our initial ideas how one could exploit cognitive biases as explained in behavioral economics, we developed a prototypical application. The chosen use case is personal finances. Our MoneySaver app utilizes behavioral economics theories to help people save up money in a novel way. The following short sections describe how the theories were implemented in the design.

\subsection{General Functionality}

The core functionality of our MoneySaver app is to keep track of multiple savings targets. The app reminds people to save money and suggests to put the money into a physical piggy bank. Mainly, the app was created as a proof of concept with a formal evaluation in mind.

\subsection{Mental Accounting and Self Control}

Mental accounting, as shown in Section 3.1, helps people to prevent themselves from overspending. In order to become successful, mental accounting could be leveraged by explicitly suggesting the accounts and visualizing them. In our app, we provide reminders to save money or put their money in a different pocket (see Section 3.1) until they return to their physical piggy bank. To support mental accounting, we empower users to set up multiple savings targets, which we called virtual piggy banks. Once the app reminds people to save now or when they decide to save at a particular moment, the users are required to choose in which piggy bank they wish to put their money. The current balance of each piggy bank (mental account) is displayed in the app, whilst the money simply accumulates in the physical piggy bank without any accounts. This somewhat resembles the "Money Savvy Piggy Bank"19 (shown in Figure 2), which has multiple slots assigned to a category. Parents can buy this to teach their children about money.

Besides, saving with a piggy bank could facilitate the sunk costs fallacy and payment decoupling. Since inserting money into a piggy bank adds a single step before spending the money, people could think that they "pay the piggy bank". Once the app tells them that they have saved up a certain amount, the users might be inclined to think that the piggy bank pays for their desired good and they get it "for free". That way, overspending in a single category can also be justified. The sunk costs nature of piggy banks becomes evident if we look at the hypothetical actions after one has achieved a savings target. Does he/she continue to save money with an attitude like "I've already saved up that much, I might as well keep going and

\footnotetext{
${ }^{19}$ http://www.msgen.com/assembled/money_savvy_pig.html, last accessed August 142013
} 


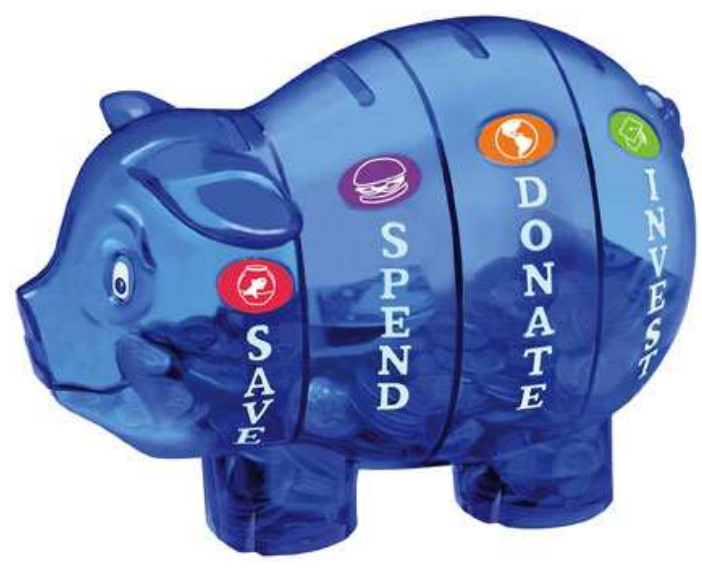

Fig. 2 The Money Savvy Pig has multiple slots which make mental accounting apparent.

buy something more expensive"? Or, as we believe, the exact opposite might come to their minds: "I might as well spend all that money, since I already saved it." We argue for the latter because short term benefits are more attractive than long-term gains (O’Donoghue \& Rabin 1999).

\subsection{Loss aversion}

As stated above (Section 3.2), loss aversion can play a role in gamified applications. In our MoneySaver app, we introduced a standard gamification badge system (achievements). However, the app takes them from the user if she fails to respond to reminders or misses deadlines. We expect that people will try to continue saving to keep the badges because losses influence them more heavily than gains (Ariely et al. 2005, Kahneman et al. 1991). This principle has been addressed before by Hamari (2011) in the context of social online games.

\subsection{Anchoring}

We deliberately put anchors or points of relevance in the app. For example, the app can suggest to save a random amount for each reminder. Even if people decide to put a different amount of money into their piggy bank, we hypothesize that they were primed with the number, which the app had displayed. Furthermore, we let the user choose the range in which the reminders should suggest amounts. In this dialog, too, we prime the users with $€ 10$ (see Figure 3 ). Lastly, we "instantiate" the savings targets with the option to choose an image of the desired good. Coins and 
bills do not convey the notion of value as well as physical objects. Thus, users are able to assess the real value of the money in their piggy bank, if they are reminded through a picture of what they are saving for. 


\section{Evaluation of the MoneySaver Prototype}

Having explained how behavioral economics influenced the design of a prototypical personal finances app, we come to evaluate the effectiveness of the design approach. In particular we evaluated the following research questions (RQ):

$\begin{array}{ll}\text { RQ1 Can saving be supported by triggering mental accounting through } \\ \text { RQ2 } & \text { Can apps nudge people to save more through anchoring? } \\ \text { RQ3 } & \text { Do default values in the settings of a mobile application impact } \\ & \text { behavior outside the pure interaction with the device? }\end{array}$

In regard to those research questions we formulated a set of hypotheses $(\mathrm{H})$ :

H1 Mental accounting in saving is a strong success factor and can be supported through a mobile app.

$\mathrm{H} 2$ Anchors that are present in a user interface act as priming factors and therefore do influence the users' interactions.

H3 Random numbers work as anchors and therefore might bias answers in a questionnaire.

H4 Losing achievements motivates people to keep "playing" because of human loss aversion. It motivates users to pursue their behavior and consequently to succeed with their endeavor.

H5 Following default values in settings menus influences realworld behavior.

\subsection{Methodology}

After developing the app relying on the concepts presented in Section 4, we ran a user study in an office environment at the university. To test our hypotheses, we chose a "between-groups" setting (Field \& Hole 2003, p. 70) for the task-related part of the study. One reason for this choice was the fact that a within-subjects design would have required proper counterbalancing to avoid learning effects or - in our case - unintentional anchoring or priming.

\subsubsection{Tasks}

The study duration was approx. 20-30 minutes per participant, who were briefed by the experimenter and debriefed in an email after the study was complete. We asked people to perform a set of 7 predefined tasks:

T1 Create a new savings target

T2 Look up your current achievements

T3 Put $€ 7$ into the (virtual) piggy bank 
Look up detailed information on the progress of the savings target

T5 Set up the notifications to display a random amount to which you have to commit

T6 Find out how to achieve your savings target (hypothetically)

T7 Mark your savings target as "Purchased"

Our independent variables were:

V1 Anchor. One group was presented an anchor in a dialog, the other was not.

V2 The last two digits of the participant's telephone number, which we divided into the categories low (00-24), medium (25-74), and high (75-99).

V3 Context. The lab-study participants were primed with the topic of saving money during the experiment. Another group was asked a subset of the questions in an on-line survey.

On a quantitative scale, we measured the amount which people claim to save when using our prototype. Furthermore, we evaluated arbitrary anchors, as shown in one of numerous experiments from e.g. Ariely et al. (2003), through a questionnaire which formed the end of each session. Our intention was to evaluate whether the last two digits of the telephone number of the subjects functioned as anchors and subsequently influenced their reported savings behavior.

Lastly, one of our final questions (see Table 1) in the survey evaluated mental accounting without making a reference to the app. At this point of the study, we had primed the subjects to reflect on their saving habits. As shown in Section 3.1, parts of the mental accounting theory suggest that people are likely to treat money differently if they received it unexpectedly. That is, they put it in a different mental account that is often referred to as "house money". Thus, the theory indicates a tendency towards answer (b) and that option (e) is the least favored. By asking this question very late in the experiment, we investigated if the priming on the topic of saving money moved the tendency from (b) to (a).

In order to test our hypotheses against a non-primed control group we put up an on-line questionnaire which contained two of the questions from the experiment (one of them was the question in Table 1), the other concerned a self-assessment on one's mental accounting efforts.

\subsubsection{Participants}

We recruited 26 participants through spreading a Doodle link on social media and personal invitations. There were 11 female and 15 male participants and the average age was 24 years (standarddeviation $(S D)=5.5$ ) (we did not ask the exact date of birth). 23 participants were university students, the other three participants did not agree to reveal their profession. Subjects did not receive any direct compensation for their participation except free soft-drinks and snacks during their attendance. Also, 


\begin{tabular}{|l|l|}
\hline Q1 & $\begin{array}{l}\text { Suppose you win } € 200 \text { at a raffle. What do you do with the won } \\
\text { money? } \\
\text { (a) I'm saving the money } \\
\text { (b) I buy something, I normally would not. } \\
\text { (c) I use it to do some maintenance investments (e.g. on my car) } \\
\text { (d) I won't do anything special with that money } \\
\text { (e) Something else: }\end{array}$ \\
\hline Q2 (5 Point Likert Scale) & $\begin{array}{l}\text { I thoroughly categorize my spendings (e.g. leisure, household, } \\
\text { restaurants). }\end{array}$ \\
\hline
\end{tabular}

Table 1 Q1: Mental accounting of unexpected gains. Q2: Self-assessed mental accounting efforts.

we raffled off a small Amazon gift card. The target group shows a rather homogenous monthly income structure (61\% make less than €500, 31\% report a monthly income between $€ 500$ and $€ 1499$, the remaining $8 \%$ earns more than $€ 1500$ ). Thus, we regard the possibility to save money for each participant as almost equal.

Our control group was formed by 115 people who filled out an on-line questionnaire. We spread the link via social media and allowed the survey a time span of three days.
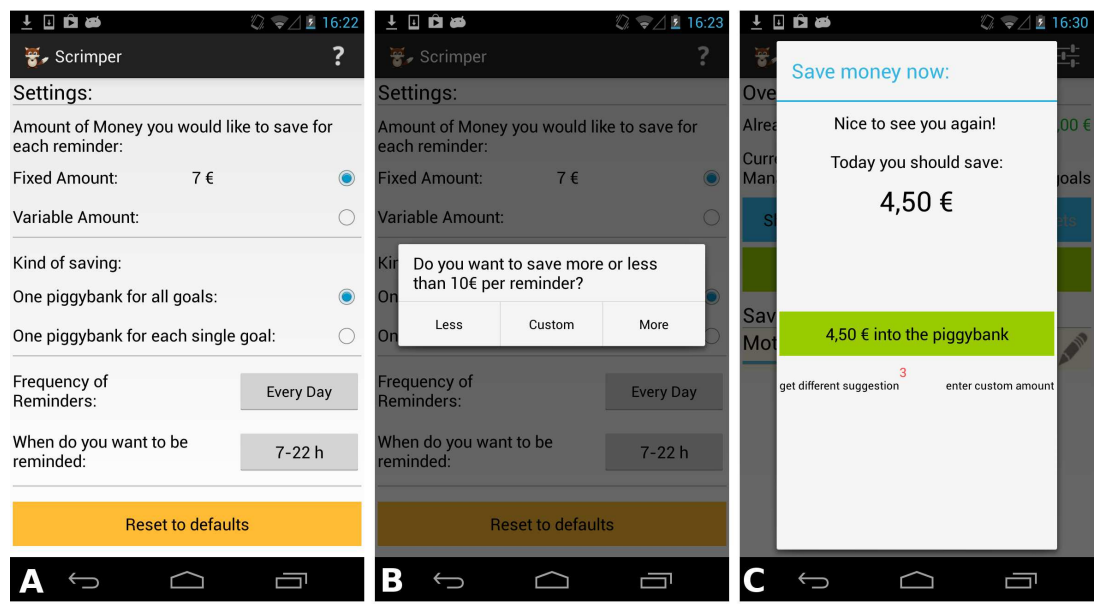

Fig. 3 (A) Settings menu. If the user clicks on "Variable Amount" she is taken to (B) the $€ 10$ Anchor. If she selects less than $€ 10$, the reminder looks something similar to (C) 


\subsection{Results}

We found the following in the data that we collected in the laboratory user study:

- $81 \%$ of the participants wished a separate piggybank for each savings goal. This supports $\mathrm{H} 1$.

- $50 \%$ would save the amount that was suggested to them, providing evidence for H5.

- $84 \%$ of the subjects confirmed that a picture of the savings target is motivating.

- $53 \%$ say that achievements would motivate them to keep up saving money. Furthermore, we asked the participants to asses their likelihood to share their achievements on social media on a 5-point Likert scale ranging from 1 (very likely) to 5 (not likely at all). Contradictory to (Zichermann \& Cunningham 2011, p. 67), we observed a strong tendency towards rejection of social media interaction $($ Mean $(M)=4.38, S D=1.06)$.

- We asked participants to assess how they react upon the loss of achievements on a 5-point Likert scale ranging from 1 (I agree) to 5 (I disagree). When asked if they changed their savings behavior to keep their earned badges the statistics we observed an average score of $M=3.04(S D=0.96)$. The participants reported with $M=3.58(S D=0.90)$ that they would make a higher one-time saving to prevent the loss of a badge. Accordingly, this partly supports H4.

- Answering question Q1 (Table 1), we found that $46 \%$ would buy something they normally would not have bought. $42 \%$ would save their money. In order to find out if subjects in the experimental group had been primed by the topic of "saving up money" in our experiment, we performed a Chi-Squared test on the data. We could not run a $t$-test because the data was non-parametric (not normally distributed). At a significance-level of .05, the test showed that there were no significant differences in distributions of the participants' choices $\left(\chi^{2}(4)=5.96, p>0.1\right)$. Since the control- and experimental group did not significantly differ, we conclude that priming was not sufficiently effective in our experiment. In the distribution that is shown in Figure 4, however, we observe that a slightly higher percentage of the interviewees claim not to do anything special with an unforeseen gain.

- Finally, we investigated whether the last two digits of a participant's telephone number might serve as an anchor for their choice on how much to save at each reminder. Since we had three different measures, i.e., low, medium and high number, we performed analysis through a between-subjects ANOVA. This test, however, did not show any significant effects between the groups $(F(2)=0.384, p>$ 0.1 , post-hoc tests were not necessary). Participants with lower numbers acted similar to the ones with higher numbers. Besides, the number of participants in each condition might have been too small to gather robust data. As a consequence, we reject $\mathrm{H} 3$. 


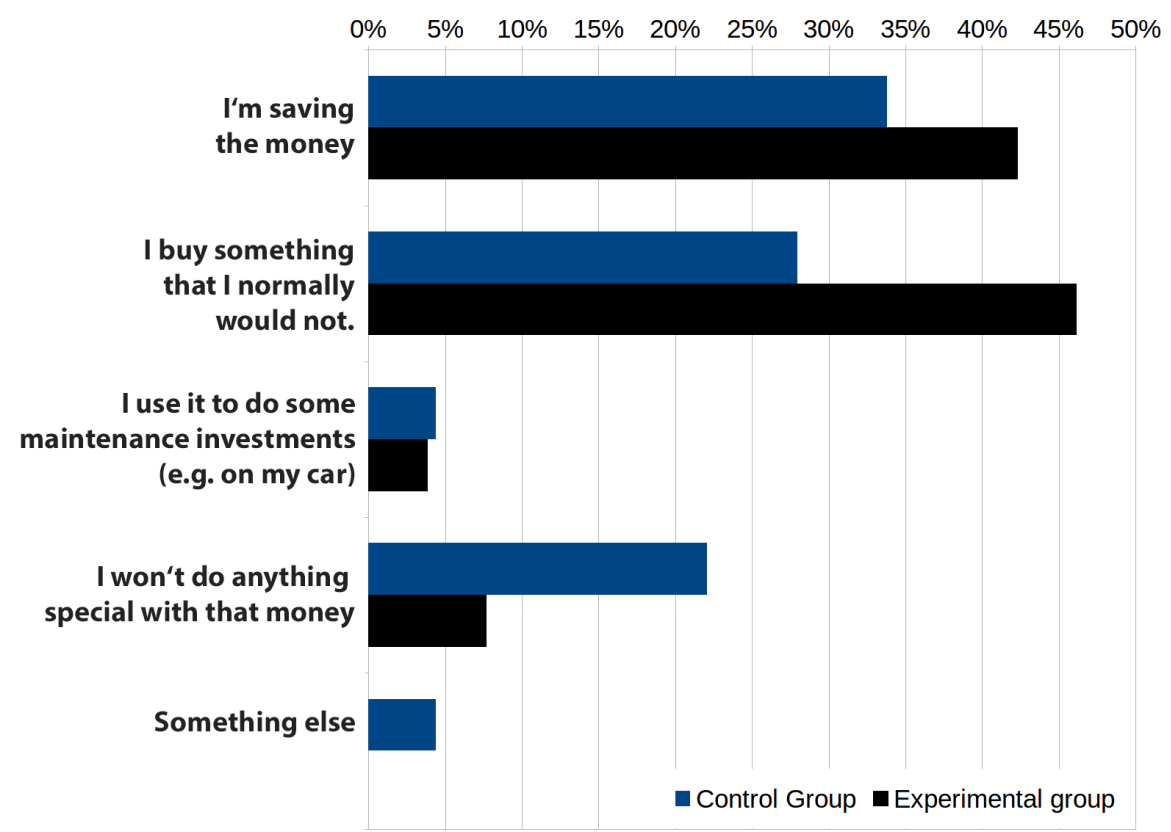

Fig. 4 Answer distribution for Q1. Only option $d$ defies mental accounting efforts. Most people treat an unexpected gain differently than the rest of their money (house money effect, see Section 3.1). Answer (e) did not occur in the experimental group.

\subsection{Discussion}

The main result of the study was that people favor an app that helps them save money. Mental accounting can help them achieve this goal, which we successfully implemented in a prototypical app. To a large part $(77 \%, n=89)$, subjects in our control group relied on mental accounting strategies. In the experimental group, even more people $(92 \%, n=24)$ treated the won money differently ${ }^{20}$. The fact that question Q1 in Table 1 was not answered with indifference by all the participants strongly suggests that people in both our control and experimental group $(\mathrm{N}>120)$ rely on mental accounting. Both the lab study and the on-line questionnaire indicate that people $d o$ attribute unforeseen gains to a mental account. However, we did not see significant differences between our control and experimental groups when it comes to whether to save or spend the money.

We found more evidence that mental accounting can be supported through our app when we asked whether people wanted to have one piggy bank for all their savings targets or a separate piggy bank for each of the desired items. $81 \%(n=21)$

${ }^{20}$ A Chi-Square test did not reveal significant differences between the control and experimental group $\left(\chi^{2}(1)=2.1015, p>0.1\right)$ 
of the lab study participants reported that they would prefer a separate piggy bank and that the app should continue to support that.

All this leads us to believe that H1 (mental accounting is useful and can be supported through an app) is partly confirmed.

\subsubsection{More Gamification Elements}

For many people, saving money is a challenge. They either choose it deliberately or because their financial situation demands it. This is why the gamification elements in the MoneySaver app could make further use of the "challenge" paradigm. In a future version we will display a number of challenges to the user, that are clearly labeled, e.g. "Challenge for the next week: Save $€ 25$ to achieve the badge 'supersaver".'

\subsubsection{Anchors}

Coming back to the usage of anchors, we did not observe a significant correlation ( $p>0.05$ ) between the presented split value of $€ 10$ and the choice on how much the participants would like to save with each notification. An interesting phenomenon, however, can be seen in Figure 5. Only one participant within the group which saw the anchor set the reminder value to more than $€ 10$. Since the effect was not statistically significant $(t(24)=0.578, p>0.1)$, we need to assume that this is due to chance.

We hypothesize that presenting a much higher number as "split value" (in accordance to the Ghandi question in Section 3.4.1) could nudge the people to unconsciously adjust their reminders towards the higher number. This, however, needs to be shown in another experiment for which our data can serve as control data. One participant perceived the anchor-dialog from Figure 3 (B) as cumbersome. He thought it was a usability issue that there is another dialog keeping the user from achieving her task.

Furthermore, it is possible that the anchors in our experiment failed to provide more visible results because there were too many: the last two digits of one's telephone number, the "split value" in the settings dialog for the experimental group, the amounts which were suggested to save during the experiment - all the numbers might have caused an "anchor overflow", thus mitigating the priming and framing effects.

In a future version, we plan to make use of the asymmetric choice effects mentioned in Section 3.4.2. The settings menu of the app could be extended by options that are either more comparable to other options or less desirable. We would like the user to save as often as possible, without becoming bothered by notifications. Thus, the app intends to remind them at least every second day to save money. The options could be: getting reminded every now and then [A], every second day through the notification bar $[\mathrm{B}]$ and every second day through the notification bar with an alarm sound plus vibration [B-]. We hypothesize that users can compare option [B] 


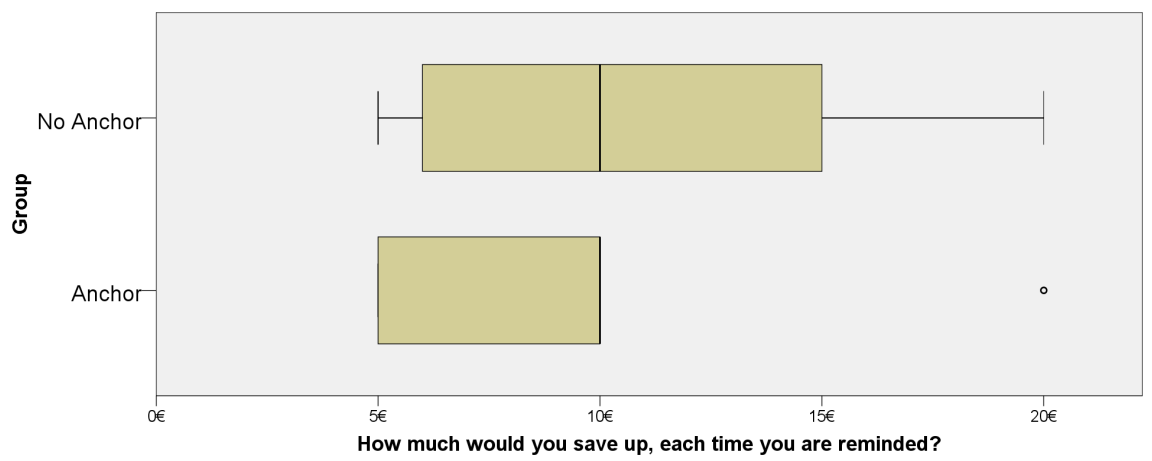

Fig. 5 The anchor group in our lab experiment did only once choose to save more than the split value of $€ 10$

and [B-] more easily than the vague "every now and then", which is why we expect them to choose option [B]. Another example could be the options-dialog for the amount of money to save. Presenting an option set containing fixed amount [A], random amount with decimals [B-] and random amount (integers only) [B]. Here, too, we suppose that option [B-] will be the least favorable and votes for option [B] increase.

\subsubsection{Loss aversion}

We investigated how people react once they face losing an already acquired badge. The reported behavior indicates that the prospect of loss is (for some) a sufficient threat to maintain self-control and follow the self-imposed rules to save more money. However, the evidence at hand does not allow to fully confirm H4, yet. Further, longterm behavioral research with our app is necessary to gain deep insights into loss aversion in respect to virtual goods. 


\section{Summary and Conclusion}

In this chapter, we took a look at behavioral economics in Human-Computer Interaction, especially motivated through mobile computing scenarios. We have shown that the many concepts and theories from behavioral economics offer plenty of opportunities to enrich the understanding of persuasive computing in general, and gamification in particular. Since only a subset of opportunities that reside in behavioral economics could be addressed in this chapter, we will conduct and encourage further research in this area. Extending our financial context, we are in the making of an electronic piggy-bank that communicates with smartphones (see Stockinger et al. (2013)). It will allow to control the progress of saving up money and will permit us to investigate self-control and self-deception of users - do they save as much as they claim? Do they follow the reminders and put money into the piggy-bank whenever the smartphone displays a notification? Do they follow through until they have reached their goal? These are just some of the questions that need to be answered in a long-term experiment.

Also, we set out to find new use cases for bounded rationality and cognitive biases in a technology-driven context. Short passwords for highly sensitive data are not apt to defend oneself against the many threats of cyber crime. Yet, people still use them and are inclined to act irrationally that way.

Finally, we aim to explore how people are influenced by user studies, that take place so often in HCI research. Work by Birnbaum (1999) shows that cognitive biases distort people's behavior during user studies to a high degree, resulting in all unwanted type I, II and III errors. Recently, Möller et al. (2013) showed that the design of a user study has a great impact on the behavior of the participants. Besides, the context we work in drives us to investigate how intuitive interaction can be explained through neurology and behavioral sciences. We assume that interaction design that prevents the Reflective System (or System 2 (Kahneman 2011)) from becoming active generates greater usability.

\section{References}

Ariely, D. (2009), Predictably Irrational: The Hidden Forces That Shape Our Decisions, HarperCollins, New York, NY, USA.

Ariely, D., Huber, J. \& Wertenbroch, K. (2005), 'When Do Losses Loom Larger Than Gains?', Journal of Marketing Research 42(2), pp. 134-138.

Ariely, D., Loewenstein, G. \& Prelec, D. (2003), 'Coherent Arbitrariness: Stable Demand Curves Without Stable Preferences', The Quarterly Journal of Economics 118(1), pp. 73-106.

Bao, X., Gowda, M., Mahajan, R. \& Choudhury, R. R. (2013), The Case for Psychological Computing, in 'Proceedings of the 14th Workshop on Mobile Computing Systems and Applications (HotMobile '13)', ACM, New York, NY, USA, pp. 6:1-6:6. 
Birnbaum, M. H. (1999), 'How to Show That $9>221$ : Collect Judgments in a Between-Subjects Design', Psychological Methods 4(3), 243.

Consolvo, S., Everitt, K., Smith, I. \& Landay, J. A. (2006), Design Requirements for Technologies That Encourage Physical activity, in 'Proceedings of the SIGCHI Conference on Human Factors in Computing Systems (CHI '06)', ACM, New York, NY, USA, pp. 457-466.

Consolvo, S., McDonald, D. W. \& Landay, J. A. (2009), Theory-Driven Design Strategies for Technologies That Support Behavior Change in Everyday Life, in 'Proceedings of the SIGCHI Conference on Human Factors in Computing Systems (CHI '09)', ACM, New York, NY, USA, pp. 405-414.

Deterding, S., Dixon, D., Khaled, R. \& Nacke, L. (2011), From Game Design Elements to Gamefulness: Defining Gamification, in 'Proceedings of the 15th International Academic MindTrek Conference: Envisioning Future Media Environments', ACM, pp. 9-15.

Diewald, S., Möller, A., Roalter, L. \& Kranz, M. (2012), Gamification-supported Exploration of Natural User Interfaces, in 'Adjunct Proceedings of the 4th International Conference on Automotive User Interfaces and Interactive Vehicular Applications (AutomotiveUI '12)', pp. 47-48.

Field, A. P. \& Hole, G. (2003), How to Design and Report Experiments, Sage Publications, London, England.

Fitz-Walter, Z., Tjondronegoro, D. \& Wyeth, P. (2011), Orientation Passport: Using Gamification to Engage University Students, in 'Proceedings of the 23rd Australian Computer-Human Interaction Conference (OzCHI '11)', ACM, New York, NY, USA, pp. 122-125.

Fogg, B. J. (2002), Persuasive Technology: Using Computers to Change What We Think and Do, Science \& Technology Books, San Francisco, CA, USA.

Froehlich, J., Dillahunt, T., Klasnja, P., Mankoff, J., Consolvo, S., Harrison, B. \& Landay, J. A. (2009), UbiGreen: Investigating a Mobile Tool for Tracking and Supporting Green Transportation Habits, in 'Proceedings of the SIGCHI Conference on Human Factors in Computing Systems (CHI '09)', ACM, New York, NY, USA, pp. 1043-1052.

Froehlich, J., Findlater, L. \& Landay, J. (2010), The Design of Eco-Feedback Technology, in 'Proceedings of the SIGCHI Conference on Human Factors in Computing Systems (CHI '10)', ACM, New York, NY, USA, pp. 1999-2008.

Gächter, S., Orzen, H., Renner, E. \& Starmer, C. (2009), 'Are Experimental Economists Prone to Framing Effects? A Natural Field Experiment', Journal of Economic Behavior \& Organization 70(3), 443-446.

Hamari, J. (2011), Perspectives From Behavioral Economics to Analyzing Game Design Patterns: Loss Aversion in Social Games, in 'CHI '11 Extended Abstracts on Human Factors in Computing Systems (CHI EA '11)', ACM, New York, NY, USA, pp. 1-6.

Hurter, C., Girouard, A., Riche, N. \& Plaisant, C. (2011), Active Progress Bars: Facilitating the Switch to Temporary Activities, in 'Extended Abstracts on Human Factors in Computing Systems (CHI EA '11)', ACM, New York, NY, USA, pp. 1963-1968. 
Kahneman, D. (2011), Thinking, Fast and Slow, Allen Lane, London, England.

Kahneman, D., Knetsch, J. L. \& Thaler, R. H. (1991), 'Anomalies: The Endowment Effect, Loss Aversion, and Status Quo Bias', The Journal of Economic Perspectives 5(1), pp. 193-206.

Kahneman, D. \& Tversky, A. (1979), 'Prospect Theory: An Analysis of Decision Under Risk', Econometrica: Journal of the Econometric Society 47(2), pp. 263291.

Kahneman, D. \& Tversky, A. (1984), 'Choices, Values, and Frames', Smelser, Neil J./Gerstein Dean R.(eds.): Behavioral and Social Science: Fifty Years of Discovery. National Academy Press: Washington, DC 39(1), pp. 153-172.

Kranz, M., Murmann, L. \& Michahelles, F. (2013), 'Research in the Large: Challenges for Large-Scale Mobile Application Research - A Case Study about NFC Adoption using Gamification via an App Store', International Journal of Mobile Human Computer Interaction (IJMHCI) 5(1), pp. 45-61.

Lee, M. K., Kiesler, S. \& Forlizzi, J. (2011), Mining Behavioral Economics to Design Persuasive Technology for Healthy Choices, in 'Proceedings of the SIGCHI Conference on Human Factors in Computing Systems (CHI '11)', ACM, New York, NY, USA, pp. 325-334.

Marczewski, A. (2012), Gamification: A Simple Introduction and a Bit More.

Mattes, S. \& Hallén, A. (2009), Surrogate Distraction Measurement Techniques: The Lane Change Test, in 'Driver Distraction: Theory, Effects, and Mitigation', CRC Press, Atlanta, GA, USA, pp. 107-121.

Maurer, M.-E., De Luca, A. \& Stockinger, T. (2011), Shining Chrome: Using Web Browser Personas to Enhance SSL Certificate Visualization, in 'HumanComputer Interaction (INTERACT '11)', Vol. 6949 of Lecture Notes in Computer Science, Springer, pp. 44-51.

Meschtscherjakov, A., Wilfinger, D., Scherndl, T. \& Tscheligi, M. (2009), Acceptance of Future Persuasive In-Car Interfaces Towards a More Economic Driving Behaviour, in 'Proceedings of the 1st International Conference on Automotive User Interfaces and Interactive Vehicular Applications (AutomotiveUI '09)', ACM, New York, NY, USA, pp. 81-88.

Möller, A., Kranz, M., Schmid, B., Roalter, L. \& Diewald, S. (2013), Investigating Self-Reporting Behavior in Long-Term Studies, in 'Proceedings of the SIGCHI Conference on Human Factors in Computing Systems (CHI '13)', ACM, New York, NY, USA, pp. 2931-2940.

Moraveji, N., Akasaka, R., Pea, R. \& Fogg, B. (2011), The Role of Commitment Devices and Self-Shaping in Persuasive Technology, in 'Extended Abstracts on Human Factors in Computing Systems (CHI EA '11)', ACM, New York, NY, USA, pp. 1591-1596.

Muran, E. M. \& Motta, R. W. (1993), 'Cognitive Distortions and Irrational Beliefs in Post-Traumatic Stress, Anxiety, and Depressive Disorders', Journal of Clinical Psychology 49(2), pp. 166-176.

Nielsen, J. \& Molich, R. (1990), Heuristic Evaluation of User Interfaces, in 'Proceedings of the SIGCHI Conference on Human Factors in Computing Systems (CHI '90)', ACM, pp. 249-256. 
Norman, D. A. (2007), Emotional Design: Why We Love (or Hate) Everyday Things, Basic books, New York, NY, USA.

Norton, M. I., Mochon, D. \& Ariely, D. (2012), 'The IKEA Effect: When Labor Leads to Love', Journal of Consumer Psychology 22(3), pp. 453-460.

O’Donoghue, T. \& Rabin, M. (1999), 'Doing It Now or Later', The American Economic Review 89(1), pp. 103-124.

Pronin, E. \& Kugler, M. B. (2007), 'Valuing Thoughts, Ignoring Behavior: The Introspection Illusion as a Source of the Bias Blind Spot', Journal of Experimental Social Psychology 43(4), pp. 565-578.

Ross, L. (1977), The Intuitive Psychologist and his Shortcomings: Distortions in the Attribution Process, in L. Berkowitz, ed., 'Advances in Experimental Social Psychology', Vol. 10, Elsevier Science, pp. 173-220.

Saini, R. \& Monga, A. (2008), 'How I Decide Depends on What I Spend: Use of Heuristics is Greater for Time Than for Money', Journal of Consumer Research 34(6), pp. 914-922.

Shafir, E. \& Thaler, R. H. (2006), 'Invest Now, Drink Later, Spend Never: On the Mental Accounting of Delayed Consumption', Journal of Economic Psychology 27(5), pp. 694-712.

Simonson, I. (1990), 'The Effect of Purchase Quantity and Timing on VarietySeeking Behavior', Journal of Marketing Research 27(2), pp. 150-162.

Stockinger, T., Koelle, M., Lindemann, P., Witzani, L. \& Kranz, M. (2013), SmartPiggy: A Piggy Bank That Talks to Your Smartphone, in 'Proceedings of the 12th International Conference on Mobile and Ubiquitous Multimedia (MUM '13)', ACM, New York, NY, USA, pp. 42:1-42:2.

Thaler, R. (1985), 'Mental Accounting and Consumer Choice', Marketing Science 4(3), pp. 199-214.

Thaler, R. (1999), 'Mental Accounting Matters', Journal of Behavioral Decision Making 12(3), pp. 183-206.

Tractinsky, N. (1997), Aesthetics and apparent usability: empirically assessing cultural and methodological issues, in 'Proceedings of the SIGCHI Conference on Human factors in computing systems (CHI '97)', ACM, New York, NY, USA, pp. 115-122.

Wilkinson, N. \& Klaes, M. (2008), An introduction to behavioral economics, Palgrave Macmillan New York, New York, NY, USA.

Zichermann, G. \& Cunningham, C. (2011), Gamification by design: Implementing game mechanics in web and mobile apps, O'Reilly Media, Sebastopol, Canada. 